\title{
Mekong Delta Runoff Prediction Using Standardized Remotely-Sensed Water Balance Variables
}

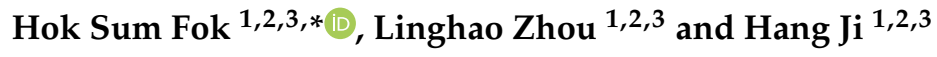 \\ 1 School of Geodesy and Geomatics, Wuhan University, Wuhan 430079, China; \\ lhzhou2016@whu.edu.cn (L.Z.); 2019282140105@whu.edu.cn (H.J.) \\ 2 Key Laboratory of Geospace Environment and Geodesy, Ministry of Education, Wuhan University, \\ Wuhan 430079, China \\ 3 Key Laboratory of Geophysical Geodesy, Ministry of Natural Resources, Wuhan 430079, China \\ * Correspondence: xshhuo@sgg.whu.edu.cn; Tel.: +86-027-6877-8649
}

Received: 20 June 2020; Accepted: 14 July 2020; Published: 16 July 2020

\begin{abstract}
A suitable routing model for predicting future monthly water discharge (WD) is essential for operational hydrology, including water supply, and hydrological extreme management, to mention but a few. This is particularly important for a remote area without a sufficient number of in-situ data, promoting the usage of remotely sensed surface variables. Direct correlation analysis between ground-observed WD and localized passive remotely-sensed surface variables (e.g., indices and geometric variables) has been studied extensively over the past two decades. Most of these related studies focused on the usage of constructed correlative relationships for estimating WD at ungauged locations. Nevertheless, temporal prediction performance of monthly runoff $(R)$ (being an average representation of WD of a catchment) at the river delta reconstructed from the basin's upstream remotely-sensed water balance variables via a standardization approach has not been explored. This study examined the standardization approach via linear regression using the remotely-sensed water balance variables from upstream of the Mekong Basin to reconstruct and predict monthly $R$ time series at the Mekong Delta. This was subsequently compared to that based on artificial intelligence (AI) models. Accounting for less than $1 \%$ improvement via the AI-based models over that of a direct linear regression, our results showed that both the reconstructed and predicted Rs based on the proposed approach yielded a $2-6 \%$ further improvement, in particular the reduction of discrepancy in the peak and trough of WD, over those reconstructed and predicted from the remotely-sensed water balance variables without standardization. This further indicated the advantage of the proposed standardization approach to mitigate potential environmental influences. The best $R$, predicted from standardized water storage over the whole upstream area, attained the highest Pearson correlation coefficient of 0.978 and Nash-Sutcliffe efficiency of 0.947 , and the lowest normalized root-mean-square error of 0.072 .
\end{abstract}

Keywords: runoff; remote sensing hydrology; water balance variable standardization; Mekong Delta

\section{Introduction}

Owing to a lack of funding for facility maintenance [1], there has been a continuous decline in the number of ground-observed hydrological sites for observing water discharge (WD) worldwide since the 1970s [2]. Therefore, remote sensing (RS) has been advocated because of its global coverage. Normalized difference vegetation index, river width, floodplain inundation, and land surface temperature are common land surface variables derived from passive RS [3-6]. Regardless of their relationships with ground-observed WD, the passive RS surface variables are directly correlated with water level or WD as long as they are well correlated with each other in the RS field of study. However, this is not a 
justifiable reason for using unrelated RS surface variables to estimate water level or WD. Therefore, RS surface variables having direct causal relationships with water level and WD should be sought for the estimation [7].

In addition to the passive RS, satellite radar altimetry (e.g., TOPEX, Envisat, and Sentinel) and gravimetry (e.g., gravity recovery and climate experiment (GRACE)) are active RS techniques currently employed for reconstructing water level (e.g., [8]) or WD (e.g., [9]). Satellite radar altimetry observes the water level time series in inland lakes, river channels, and reservoirs (e.g., [10]). Employing the direct power function relationship with the WD (e.g., [11,12]), the observed water level time series from satellite radar altimetry can correlate well with ground-observed WD time series (e.g., [13]). Moreover, WD estimation for the entire Mekong Basin (MB) has been conducted via multi-satellite altimetric (i.e., ERS-2 and Envisat) water level time series [14]. The temporal resolution of WD estimation can be improved by assimilating multi-altimetry water level into hydrodynamic [15] or dynamic stochastic process models [16]. However, its accuracy is lower when land surface area coverage within the reflected radar footprint signals is larger (e.g., [17]).

GRACE measures time-variable gravity changes in order to infer monthly terrestrial water storage (TWS), in which TWS is one of the water balance variables (WBVs) (e.g., [18,19]). By employing the direct power function relationship between TWS and WD, the observed TWS and ground-observed WD time series can be correlated very well with each other [20,21]. The TWS can also be related to the WD (in terms of surface runoff $(R)$ ) by the other two WBVs-precipitation $(P)$ and evapotranspiration $(E T)$-via the water balance equation (i.e., $R=P-E T-\Delta T W S$ ) indirectly [22-24], in which $P$ and $E T$ can be obtained from tropical rainfall measuring mission (TRMM) and moderate resolution imaging spectrometer (MODIS) respectively. Given the above, it is clear that $P, E T$, and TWS are the RS WBVs having direct causal relationships with $R$, which should be employed rather than those aforementioned passive RS surface variables.

In operational hydrology, methods for the $R$ estimation and prediction can be classified into four categories: linear regression models, well-known hydrological models, time series models, and artificial intelligence (AI) based models. The aforementioned research studies illustrate the linear regression models and well-known hydrological models for the monthly $R$ estimation and prediction. In addition, time series models (e.g., autoregressive moving-average model (ARMA)) [25] and AI-based models (e.g., artificial neural network (ANN) [26] and recurrent neural networks (RNNs) [27]) has also been popular for monthly $R$ prediction. In particular, the AI-based models yield relatively accurate predictions when compared to other methods [28]. However, the data are directly used in the first three methods without considering potential systematic bias in the data. In the AI-based models, the data are served as input in different sequences for training the AI models, yielding non-unique results during the training stage. Therefore, a method that can mitigate the systematic bias with a unique result should be sought.

Essentially, the data standardization approach is the subtraction of the data time series from the mean divided by the standard deviation. As a result, it sharpens regional systematic characteristics of the averaged time series [29], when regional mean and variance are significantly different from the global ones [30]. This approach should partly reduce systematic biases due to environmental factors and should better capture regional variations [8]. It is anticipated that the temporal prediction results generated from this approach are better at capturing the hydrological extremes, which is the objective of this paper.

The Lancang River Basin within Yunnan, China represents an important part of the upstream MB being affected by the Indian monsoon [31] (Figure 1). The Mekong Delta (MD) is a relatively flat region with complicated estuary systems, where the WD is affected seasonally by the backwater effect of ocean tides [32-34] and the regulation effect of the Tonle Sap Lake in Cambodia before discharging to the coastal ocean $[35,36]$. Changes of hydrological controls at the upstream MB (i.e., Lancang River Basin within Yunnan, China or its extension to the southern boundary of Cambodia in this study) provide an early alarm about the conditions of hydrological extremes [31] to the downstream MB 
(i.e., MD) that causes agricultural and economic losses (e.g., [37-39]). This yields the concept of using upstream WBVs for downstream WD prediction. While the downstream $R$ has been reconstructed and estimated by using upstream RS-derived surface variables (e.g., [40]), satellite radar altimetric water level (e.g., [8,14,41]), and gravimetrically-determined TWS [16], the temporal prediction of the estuarine $R$ at the downstream using the upstream RS WBVs has not been explored.

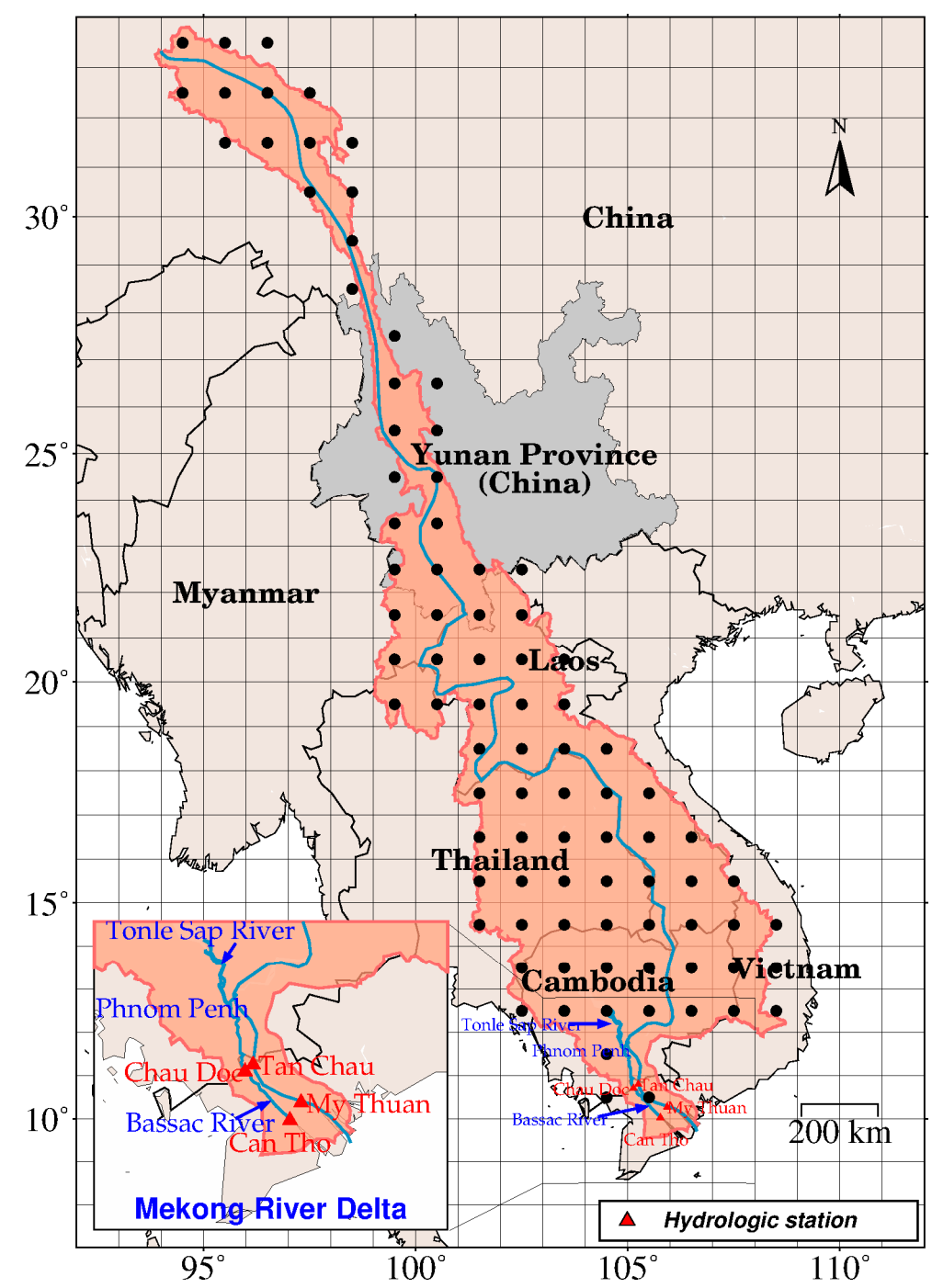

Figure 1. Mekong Basin (in pink) overlapping with Yunnan Province along with ground-observed gauges (in red triangles) within the Mekong Delta. Note that the square grids (with a black dot at each center) overlapping the whole upstream area (from the Tibetan Plateau to the southern boundary of Cambodia) until the entrance of the Mekong Delta are also collected and employed for this study.

In addition, many dams at the upstream MB were constructed during the 1990-2007 period [42]. This significantly alters the WD at the downstream MB in different seasons compared to that before dam construction $[43,44]$. However, no significant annual change of WD in the MD has been found $[42,44]$. Since the WD has already been altered in different seasons at the downstream MD, the dam operation effect would accumulate for each season. In case it is accumulated, in the form of a partial bias, this effect can be partly mitigated by the data standardization approach in this study.

Given the above justification, this study aims to examine temporal prediction performance of monthly $R$ at the MD reconstructed from the upstream standardized RS WBVs employing the data standardization approach. The $R$ time series is predicted based on the reconstructed relationship, 
followed by comparing to the data time period independent of the period used for $R$ reconstruction. To show the effectiveness of our proposed approach, it is subsequently compared with those predictions from AI-based models.

\section{Datasets and Their Post-Processing}

\subsection{Ground-Observed Discharge and Passive RS Surface Variables}

Within the MD, Tan Chau, Chau Doc, Can Tho, and My Thuan are the four ground-observed discharge stations (Figure 1). Note that the Tan Chau and Chau Doc station pair (hereafter denoted as TC-CD pair), and Can Tho and My Thuan station pair (hereafter denoted as MT-CT pair) are $\sim 220 \mathrm{~km}$ and $70-100 \mathrm{~km}$ away from the estuary mouth, respectively. The latter pair is subject to a more significant ocean tidal backwater effect than that of the former pair. To reduce semi-diurnal and diurnal ocean tidal effects from the South China Sea, the WD time series of TC-CD pair were summed up. The same procedure was applied to the MT-CT pair. Two pairs of stations were used to assess the remaining ocean tidal backwater effect.

The above WD station time series were available on request at http://www.mrcmekong.org. Since most dams were constructed before 2009, the ground-observed WD time series during 2009-2012 and 2013-2014 were chosen for $R$ reconstruction and prediction assessment, respectively. Note that the WD (in $\mathrm{m}^{3} / \mathrm{s}$ ) were daily sampled. This had to be converted into the $R$ at a monthly rate (in $\mathrm{mm} / \mathrm{mon}$ ), which was calculated by adding up the daily WD per month and subsequently dividing by the approximate MB surface area (i.e., 795,000 $\mathrm{km}^{2}$ ). Figure 2 displays both station pairs' time series during 2009-2014. Both of them had similar temporal patterns and periodicities, with a slight difference in the maximum and minimum values (Figure 2).

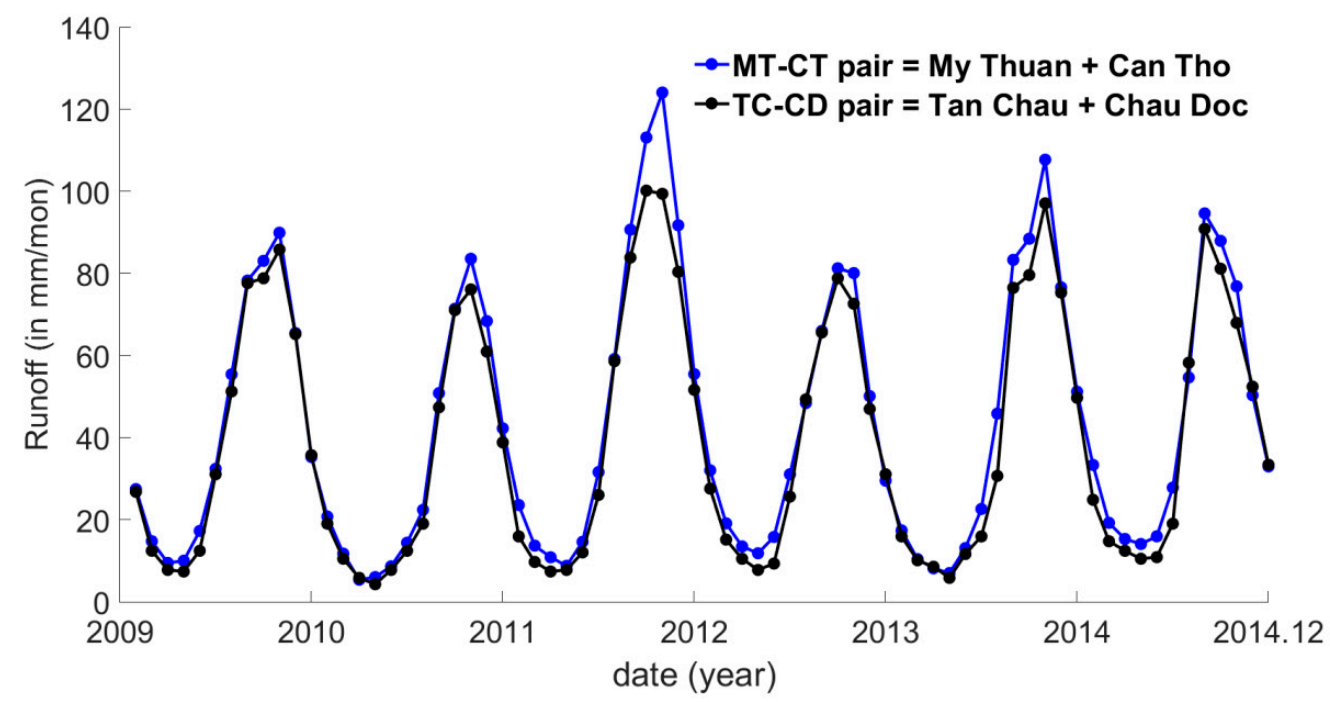

Figure 2. Time series of runoff for My Thuan-Can Tho (MT-CT) and Tan Chau-Chau Doc (TC-CD) station pairs.

The land surface temperature (LST) (i.e., MOD11C3) and normalized difference vegetation index (NDVI) (i.e., MOD13C2), which can be downloaded at https://lpdaac.usgs.gov/dataset_discovery/ modis/modis_products_table, were two of the passive RS surface data products obtained from MODIS. These data directly served as baseline results for the performance assessment against the standardized RS WBVs. 


\subsection{Water Balance Variables and Their Standardization Based on RS Data}

The three RS WBVs (S, ET, and $P$ ) were measured or inferred from GRACE, MODIS, and TRMM, respectively. To avoid the dams constructed before 2009, the monthly RS WBVs during 2009-2012 and 2013-2014 were extracted for $R$ reconstruction and prediction assessment, respectively. All passive RS surface variables and RS WBVs are visualized in Figure 3.
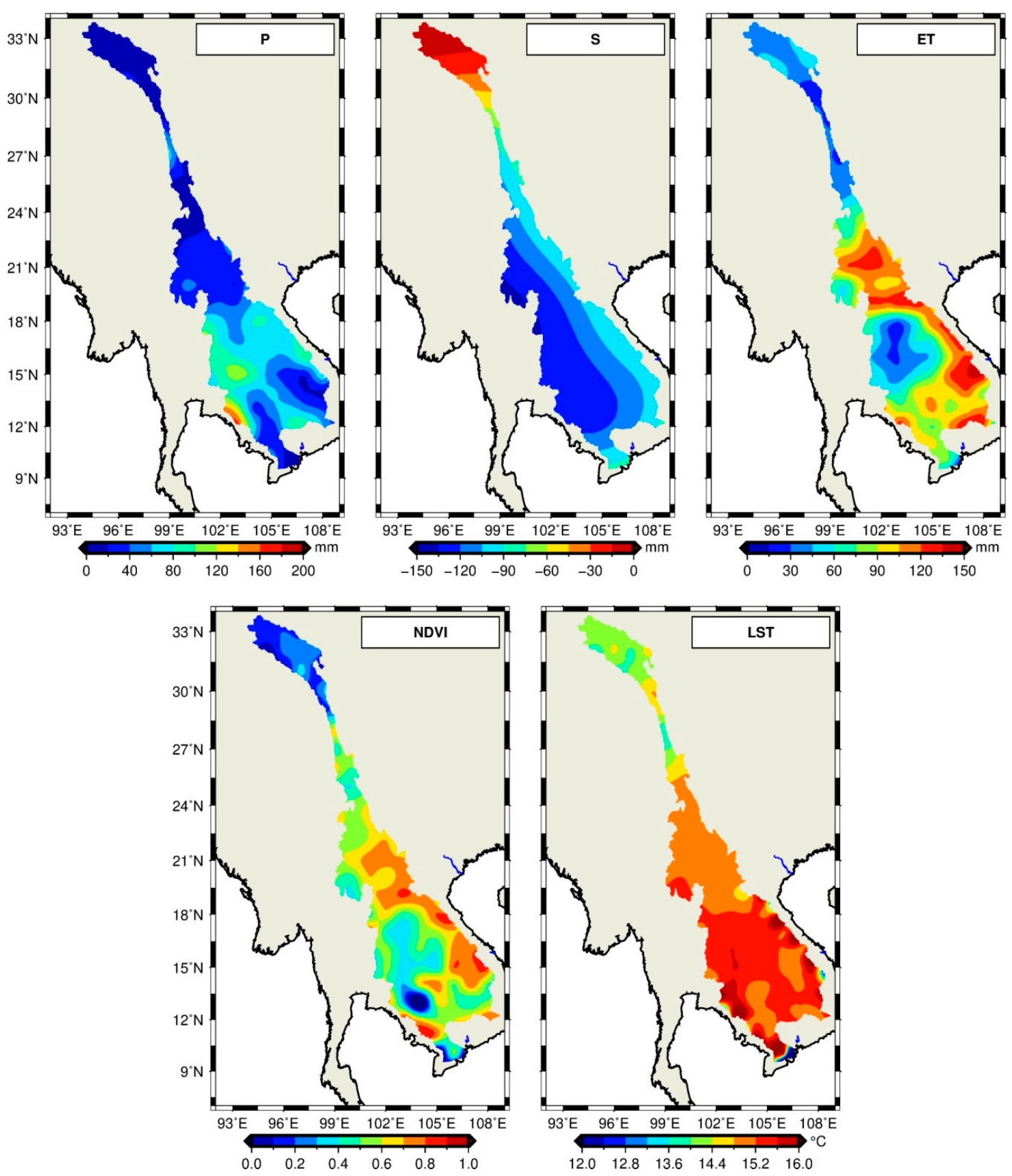

Figure 3. Spatial plot of remotely-sensed data including precipitation $(P)$, water storage $(S)$, evapotranspiration (ET), normalized difference vegetation index (NDVI), land surface temperature (LST) in March 2009.

\subsubsection{GRACE Terrestrial Water Storage (S) and Its Standardization}

Given time-variable gravity observations from GRACE, globally gridded $S$ time series can be inferred by Equation (14) in [45] divided by the averaged density of water. The Center for Space 
Research (CSR) Release (RL) 06 solution (hereinafter called CSR RL06) were utilized. The monthly RL06 data were in the form of Stokes coefficients (SCs) that represent the relative mass changes expanded up to degree 60. These data were available at http://icgem.gfz-potsdam.de/series. Post-processing steps were required before usage, which included the addition of the degree- 1 and the replacement of the $\mathrm{C}_{20}$ term in SCs for restoring the geocenter motion and geoid components [46,47], de-striping process, and Gaussian filtering with a 350-km radius for minimizing correlated errors in space [48,49].

The inferred monthly $S$ time series were then utilized to correlate with the ground-observed $R$ and to calculate its standardization (hereinafter abbreviated as $S I$ ), followed by correlating with the standardized $R$. The SI can be calculated as:

$$
S I_{j, k}=\frac{S_{j, k}-\operatorname{median}\left(S_{k}\right)}{S_{k}}
$$

where $S_{j, k}$, median $\left(S_{k}\right)$, and $s_{k}$ are the observed $S$, and the median and sampled standard deviation of GRACE $S$ for year $j$ and month $k$, respectively. The same procedure was applied to $E T$ when calculating its corresponding standardization.

\subsubsection{MODIS Evapotranspiration (ET) and Its Standardization}

Given the observed environmental variables from MODIS, global inferred ET can be inferred by an improved algorithm in [50]. The ET data (MOD16A2), with $0.5^{\circ}$ gridded resolution, were utilized and available from NASA Land Processes Distributed Active Archive Center (https://lpdaac.usgs.gov/ dataset_discovery/modis/modis_products_table).

Similar to the above, ET values can be used to calculate its standardized form (hereinafter abbreviated as SETI) using Equation (1). Despite long-term continuous ET time series beingdesirable for climatic study, the ET time series spanning from 2000 to 2014 were sufficient in the context of water balance. Consequently, SETI during 2000-2014 were calculated, whereas the calculated standardized values between 2009and 2014 were utilized in this study.

\subsubsection{TRMM Precipitation (P) and Its Standardization}

Given the measured $P$ from TRMM [51], the monthly $P$ data (TRMM 3B43 version 7), with a gridded resolution of $0.25^{\circ}$, were utilized and available from the NASA Goddard Space Flight Center at https://disc.gsfc.nasa.gov/datasets/TRMM_3B43_V7/summary. Notice that these data products were dependent on the Global Precipitation Climatology Centre (GPCP) rain gauge data, as assimilation and calibration processes were conducted (e.g., [52]).

Since $P$ does not occur every day, its standardization (hereinafter denoted as standardized precipitation index (SPI) [53]), which is different from the above Equation (1), involves calculations of the standardization of cumulative probability distribution [54]. Note that equations are not shown as it is a well-known meteorological drought index. For a similar reason to that of ET, SPI during 1998-2014 were calculated, while the standardized values between 2009 and 2014 were extracted for usage in this study.

\section{Methodology}

\subsection{Linear Regression Analysis and Data Standardization}

The processed RS WBVs and their standardizations were averaged over Yunnan Province, China and the whole upstream area (from Tibetan Plateau to southern boundary of Cambodia) (Figure 1). Before linear regression analysis, a five-month moving averaging process was conducted for further smoothing. Note that one-month (between $R$ and NDVI and LST) and two-month backward time shift (between $R$ and TRMM $P$ and MODIS ET) were applied in order to maximize the correlation due to inherent hysteretic properties of a river basin within a hydrological cycle [21]. Figure 4 displays an initial insight into the time series pattern of the RS WBVs against the ground-observed $R$ during 
2009-2012, showing that the general temporal patterns of all RS WBVs were largely consistent with the ground-observed $R$. Note that the passive RS surface variables (i.e., LST and NDVI) are not displayed because of the presence of large offsets (Table 1). A variable time lag within a year was also noticed for all RS WBVs at the upstream MB against the ground-observed $R$ at the MD. We speculate that different precipitation patterns between the upstream MB and the MD every year might be caused by El Niño-Southern Oscillation (ENSO) variability [55], and hence the adaptive changes in evapotranspiration and terrestrial water storage. After all, the MB spans across $25^{\circ}$ of latitude.

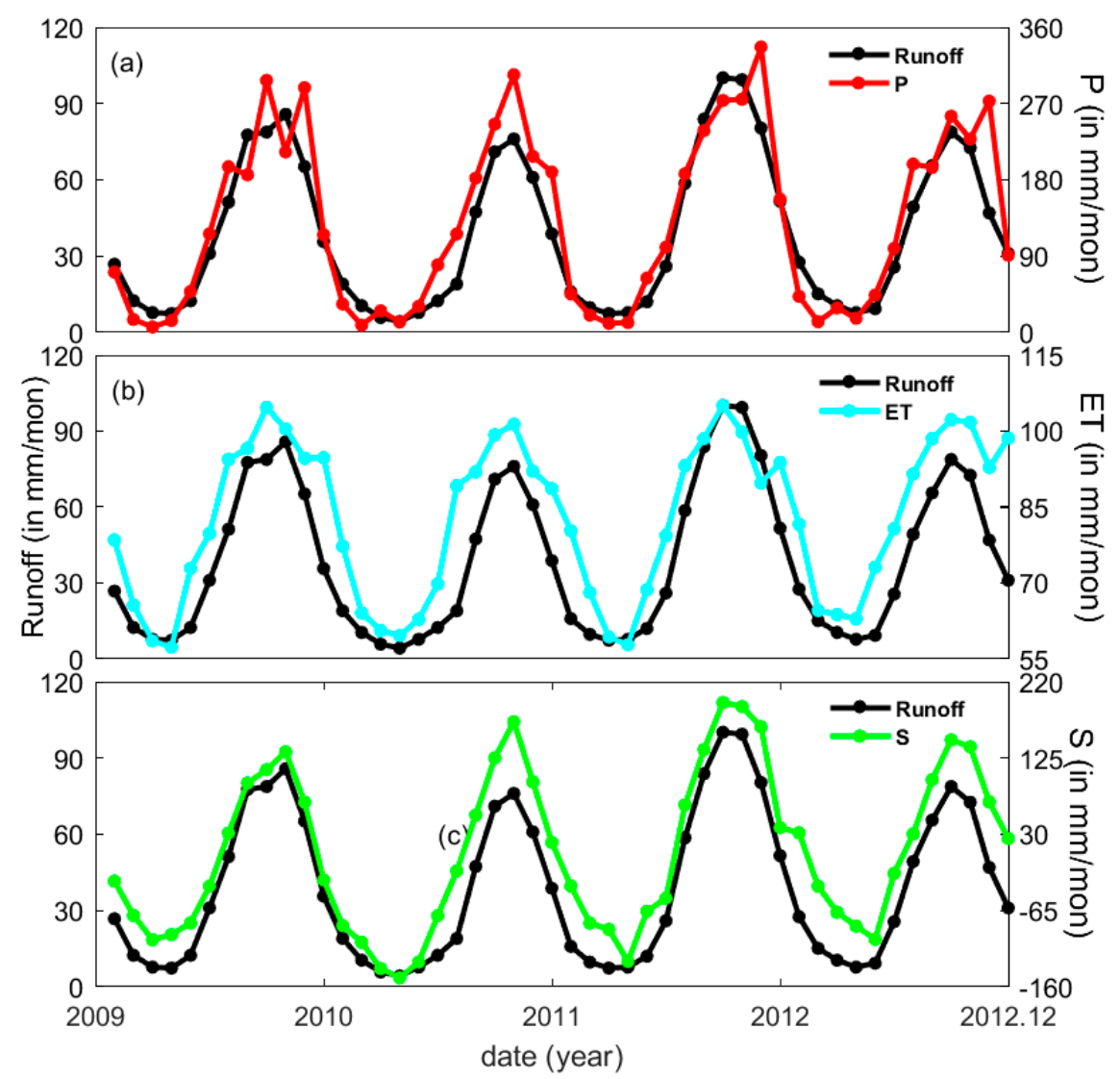

Figure 4. Time series of ground-observed runoff against remotely-sensed (a) TRMM- $P$, (b) MODIS-ET, and (c) GRACE-S values averaged over the whole upstream area from the Tibetan Plateau to the southern boundary of Cambodia at the TC-CD station pair.

Table 1. Runoff reconstruction parameters between the ground-observed runoff and the remotely-sensed water balance variables at MT-CT and TC-CD station pairs for Yunnan Province.

\begin{tabular}{ccccccc}
\hline \multirow{2}{*}{ Station } & \multirow{2}{*}{ Data } & Variable & $\boldsymbol{a}$ & $\boldsymbol{b}(\mathbf{m m} / \mathbf{m o n})$ & \multicolumn{2}{c}{$\begin{array}{c}\text { Standard Deviation } \\
(\boldsymbol{a} \text { and } \boldsymbol{b})\end{array}$} \\
& \multirow{3}{*}{ Passive RS } & NDVI & 325.6314 & -168.8107 & 23.2843 & 15.2443 \\
& & LST & -151.9813 & 2279.3453 & 9.9238 & 146.0701 \\
\cline { 3 - 7 } MT-CT & & P & 0.3144 & 9.2319 & 0.0257 & 3.5330 \\
station pair & \multirow{2}{*}{ RS WBVs } & ET & 1.2716 & -53.1952 & 0.0805 & 6.3268 \\
& & S & 0.3467 & 43.5832 & 0.0372 & 2.7332 \\
\hline & \multirow{2}{*}{ Passive RS } & NDVI & 312.2021 & -163.8793 & 18.9117 & 12.3816 \\
TC-CD & & LST & -142.5538 & 2136.8119 & 8.9802 & 132.1818 \\
\cline { 2 - 7 } station pair & & P & 0.3021 & 6.7515 & 0.0215 & 2.9484 \\
& \multirow{2}{*}{ RS WBVs } & ET & 1.2118 & -52.4742 & 0.0655 & 5.1480 \\
& & S & 0.3317 & 39.7533 & 0.0329 & 2.4186 \\
\hline
\end{tabular}


For a direct correlation between RS-observed surface variables and ground-observed $R$ in a traditional practice, a linear regression analysis is conducted to fit with two parameters, which is expressed as:

$$
y_{t} a x_{t-\delta}+b
$$

where $y_{t}$ and $x_{t-\delta}$ are the ground-observed $R$ (either at the MT-CT or TC-CD station pair) at a monthly time $t$, and each RS WBVs at a monthly time $t-\delta ; \delta$ is the time shift applied to RS-observed surface variables (i.e., LST, NDVI, TRMM $P$, and MODIS ET), as mentioned; $a$ and $b$ are the two parameters to be estimated via the linear regression analysis using the data time period between 2009 and 2012.

The two estimated parameters and their corresponding standard deviation of Equation (2) for the RS surface variables are shown in Tables 1 and 2. Though a large offset and its standard deviation were presented for the ground-observed $R$ fitted with LST, the fitted relationship should have been as well as other RS surface variables because the relative errors among them were almost the same, whether they were averaged over Yunnan Province or the whole upstream area (Tables 1 and 2). In addition, all estimated parameters were significantly different from zero in terms of statistics. These two determined parameters were then directly employed to reconstruct $R$ time series using the same values of RS surface variables for data fitting during 2009-2012, while $R$ time series were predicted by the two determined parameters using the values of RS surface variables during 2013-2014.

Table 2. Runoff reconstruction parameters between the ground-observed runoff and the remotely-sensed water balance variables at MT-CT and TC-CD station pairs for the whole upstream area from the Tibetan Plateau to the southern boundary of Cambodia.

\begin{tabular}{|c|c|c|c|c|c|c|}
\hline Station & Data & Variable & $a$ & $b(\mathrm{~mm} / \mathrm{mon})$ & $\begin{array}{r}\text { Standarc } \\
(a\end{array}$ & $\begin{array}{l}\text { Deviation } \\
\text { d b) }\end{array}$ \\
\hline \multirow{5}{*}{$\begin{array}{c}\text { MT-CT } \\
\text { station pair }\end{array}$} & \multirow{2}{*}{ Passive RS } & NDVI & 396.7570 & -184.0357 & 28.1345 & 16.1888 \\
\hline & & LST & -199.2218 & 3005.0215 & 18.2062 & 270.7465 \\
\hline & \multirow{3}{*}{ RS WBVs } & $\mathrm{P}$ & 0.2835 & 5.8395 & 0.0180 & 2.9624 \\
\hline & & ET & 1.7823 & -104.5923 & 0.1470 & 12.3381 \\
\hline & & $\mathrm{S}$ & 0.3112 & 40.2074 & 0.0123 & 1.2019 \\
\hline \multirow{5}{*}{$\begin{array}{c}\text { TC-CD } \\
\text { station pair }\end{array}$} & \multirow{2}{*}{ Passive RS } & NDVI & 379.6232 & -178.0361 & 23.0676 & 13.2733 \\
\hline & & LST & -188.2365 & 2837.8818 & 16.3860 & 243.6776 \\
\hline & \multirow{3}{*}{ RS WBVs } & $\mathrm{P}$ & 0.2680 & 4.0628 & 0.0155 & 2.5513 \\
\hline & & ET & 1.7074 & -102.1954 & 0.1244 & 10.4440 \\
\hline & & $\mathrm{S}$ & 0.2909 & 36.5738 & 0.0111 & 1.0865 \\
\hline
\end{tabular}

For our data standardization approach, the ground-observed $R$ time series were standardized.The standardized ground-observed $R, s R_{j, k}$, was achieved by:

$$
s R_{j, k}=\frac{R_{j, k}-\operatorname{med}\left(R_{k}\right)}{S_{k}}
$$

where $R_{j, k}, \operatorname{med}\left(R_{k}\right)$, and $s_{k}$ are the ground-observed $R$, the median, and sampled standard deviation of ground-observed $R$ for year $j$ and month $k$, respectively.

The standardized ground-observed $R$ was then correlated with the standardized $P$ (i.e., SPI), ET (i.e., SETI), and $S$ (i.e., SI), as mentioned in Section 2.2, via Equation (2), to determine the corresponding $a$ and $b$. In this case, these two determined parameters were then employed to calculate the corresponding standardized $R$ using the same values of RS WBVs for data fitting during 2009-2012. The calculated corresponding standardized $R$ generated from RS WBVs, together with the previously calculated $\operatorname{med}\left(R_{k}\right)$ and $s_{k}$,were then used to generate the reconstructed $R$ time series via Equation (3), while $R$ time series were predicted in the same manner using RS WBVs during 2013-2014. 
After the above procedures, the reconstructed and predicted $R$ time series were then compared against the respective ground-observed $R$ to assess the reconstruction and prediction performance during different periods, as mentioned.

\subsection{AI-Based Models}

Various neural network models have been used in the hydrology field, including streamflow forecast, flood prediction, groundwater quality estimation, water resource management, and so on. Artificial neural network (ANN) and long-short term memory (LSTM) models were employed in this study. The ANN model includes an input layer, hidden layer, and output layer. In this study, the predictors were NDVI, LST, $P, E T$, and $S$. $R$ was placed at the output layer as an output. The hidden layers consisted of two layers, and each layer contained four neurons. A scaled exponential linear unit (SELU) served as an activation function of each layer. For the hyperparameter settings, the loss function was mean absolute error. The Adam's optimizer was employed with the epoch set to 100 times. The callback function "ReduceLROnPlateau" within Keras was applied to adjust the learning rate automatically. A tenth of the training data was divided into validation data sets.

LSTM, proposed based on recurrent neural networks (RNNs), is one of the most powerful type of neural networks and is capable of processing sequences of arbitrary input patterns to overcome the gradient problem existing in traditional RNNs. In this study, the construction of the neural network formed by LSTM cells was similar to ANN; two hidden layers and the same activation function were employed. Due to non-unique results during the training stage., the two models were run ten times each. The means of the valuation parameters obtained from each training were the final valuation parameters.

\subsection{Assessment Indicators}

To examine the reconstructed and predicted $R$ time series against the ground-observed $R_{0}$, the Pearson correlation coefficient (PCC), normalized root-mean-square error (NRMSE), and Nash-Sutcliffe efficiency (NSE) model coefficient were used.

PCC measures the collinearity between two datasets. It ranges from -1 to 1 , which is calculated as

$$
P C C=\frac{\frac{1}{N} \sum_{k=1}^{N}\left(R_{0}(k)-\overline{R_{0}}\right)\left(R_{m}(k)-\overline{R_{m}}\right)}{\sqrt{\frac{1}{N} \sum_{k=1}^{N}\left(R_{0}(k)-\overline{R_{0}}\right)^{2}} \sqrt{\frac{1}{N} \sum_{i=1}^{N}\left(R_{m}(k)-\overline{R_{m}}\right)^{2}}}
$$

NRMSE measures the RMSE in terms of a fraction of error (e.g., [56]), where RMSE does not indicate the amount of relative error with respect to the observed quantities. NRMSE is defined as

$$
N R M S E=\frac{\sqrt{\frac{1}{N} \sum_{k=1}^{N}\left(R_{m}(k)-R_{0}(k)\right)^{2}}}{\max \left(R_{0}\right)-\min \left(R_{0}\right)}
$$

Since the 1970s, the NSE model coefficient [57] has become a conventional assessment indicator for evaluating the efficient gain in the performance of the estimated $R$ when compared to the ground-observed $R$ (e.g., [58-60]). It ranges from $-\infty$ to 1 . The best performance of the estimated $R$ is attained when the calculated NSE model coefficient tends to one. It is calculated as

$$
N S E=1-\frac{\sum_{k=1}^{N}\left(R_{m}(k)-R_{0}(k)\right)^{2}}{\sum_{k=1}^{N}\left(R_{m}(k)-\overline{R_{0}}\right)^{2}}
$$

where $R_{0}(i)$ and $R_{m}(i)$ are the observed and (reconstructed or predicted) $R s$ for month $k ; \overline{R_{0}}$ and $\overline{R_{m}}$ are the averages of $R_{0}$ and $R_{m}$, respectively, and $\max \left(R_{0}\right)$ and $\min \left(R_{0}\right)$ are the ground-observed maximum and minimum values of $R_{0}$ within the time series, respectively. 


\section{Results and Discussion}

This section examines the reconstruction and prediction performance of all the reconstructed and the predicted $R$ time series from the passive RS surface variables (i.e., NDVI and LST), RS WBVs (i.e., $P$, $E T, S)$, and their respective standardized forms (i.e., SPI, SETI, and SI). Note that only figures for the RS-observed surface variables averaged over the whole upstream area are shown due to the better performance of RS WBVs than those over Yunnan Province (as shown in Tables 3 and 4). Compared to that of LST and NDVI, the accuracy of RS WBVs for $R$ reconstruction and prediction appeared to be sensitive to the size of our study region used for data averaging, because the accuracy of RS WBVs was highly dependent on the spatial location when compared against the ground-observed data. For instance, research studies yielded a $27-50 \%$ relative error for the remotely-sensed $P$ in our study region [61], while a 10-30\% relative error for the global inferred ET from MODIS were presented [62,63].

Table 3. Assessment of runoff reconstruction and prediction at My Thuan-Can Tho (MT-CT) station pair, and Tan Chau-Chau Doc (TC-CD) station pair over Yunnan Province.

\begin{tabular}{|c|c|c|c|c|c|c|c|c|}
\hline \multirow{2}{*}{ Station } & \multirow{2}{*}{ Methods } & \multirow{2}{*}{ Data/Index } & \multicolumn{3}{|c|}{ Reconstruction } & \multicolumn{3}{|c|}{ Prediction } \\
\hline & & & PCC & NRMSE & NSE & PCC & NRMSE & NSE \\
\hline \multirow{18}{*}{$\begin{array}{l}\text { MT-CT } \\
\text { pair }\end{array}$} & \multirow{5}{*}{ Linear Regression } & NDVI & 0.900 & 0.116 & 0.810 & 0.934 & 0.120 & 0.853 \\
\hline & & LST & 0.914 & 0.107 & 0.836 & 0.865 & 0.164 & 0.725 \\
\hline & & $\mathrm{P}$ & 0.874 & 0.129 & 0.765 & 0.953 & 0.095 & 0.909 \\
\hline & & ET & 0.919 & 0.105 & 0.844 & 0.920 & 0.124 & 0.844 \\
\hline & & $\mathrm{S}$ & 0.809 & 0.156 & 0.654 & 0.940 & 0.107 & 0.884 \\
\hline & \multirow{5}{*}{ ANN } & NDVI & 0.924 & 0.102 & 0.851 & 0.947 & 0.106 & 0.886 \\
\hline & & LST & 0.925 & 0.103 & 0.849 & 0.886 & 0.153 & 0.762 \\
\hline & & $\mathrm{P}$ & 0.883 & 0.125 & 0.779 & 0.958 & 0.092 & 0.913 \\
\hline & & ET & 0.925 & 0.104 & 0.847 & 0.929 & 0.123 & 0.845 \\
\hline & & $\mathrm{S}$ & 0.825 & 0.155 & 0.660 & 0.949 & 0.109 & 0.878 \\
\hline & \multirow{5}{*}{ LSTM } & NDVI & 0.930 & 0.098 & 0.864 & 0.956 & 0.094 & 0.910 \\
\hline & & LST & 0.926 & 0.102 & 0.853 & 0.888 & 0.151 & 0.767 \\
\hline & & $\mathrm{P}$ & 0.880 & 0.126 & 0.774 & 0.957 & 0.092 & 0.913 \\
\hline & & ET & 0.929 & 0.101 & 0.856 & 0.939 & 0.117 & 0.862 \\
\hline & & $\mathrm{S}$ & 0.819 & 0.158 & 0.643 & 0.948 & 0.111 & 0.876 \\
\hline & \multirow{3}{*}{$\begin{array}{c}\text { Data } \\
\text { Standardization }\end{array}$} & SPI & 0.946 & 0.086 & 0.894 & 0.960 & 0.089 & 0.919 \\
\hline & & SETI & 0.935 & 0.095 & 0.871 & 0.946 & 0.103 & 0.892 \\
\hline & & SI & 0.936 & 0.094 & 0.876 & 0.957 & 0.092 & 0.914 \\
\hline \multirow{18}{*}{$\begin{array}{l}\text { TC-CD } \\
\text { pair }\end{array}$} & \multirow{5}{*}{ Linear Regression } & NDVI & 0.925 & 0.116 & 0.856 & 0.929 & 0.132 & 0.842 \\
\hline & & LST & 0.920 & 0.120 & 0.846 & 0.847 & 0.182 & 0.699 \\
\hline & & $\mathrm{P}$ & 0.901 & 0.133 & 0.811 & 0.935 & 0.118 & 0.873 \\
\hline & & ET & 0.939 & 0.105 & 0.882 & 0.911 & 0.137 & 0.828 \\
\hline & & $\mathrm{S}$ & 0.830 & 0.171 & 0.688 & 0.937 & 0.116 & 0.877 \\
\hline & \multirow{5}{*}{ ANN } & NDVI & 0.949 & 0.097 & 0.899 & 0.945 & 0.114 & 0.883 \\
\hline & & LST & 0.932 & 0.111 & 0.869 & 0.867 & 0.168 & 0.743 \\
\hline & & $\mathrm{P}$ & 0.907 & 0.129 & 0.823 & 0.942 & 0.113 & 0.885 \\
\hline & & ET & 0.945 & 0.101 & 0.890 & 0.925 & 0.129 & 0.850 \\
\hline & & $\mathrm{S}$ & 0.849 & 0.169 & 0.696 & 0.949 & 0.115 & 0.879 \\
\hline & \multirow{5}{*}{ LSTM } & NDVI & 0.954 & 0.093 & 0.909 & 0.951 & 0.106 & 0.897 \\
\hline & & LST & 0.942 & 0.103 & 0.887 & 0.881 & 0.160 & 0.767 \\
\hline & & $\mathrm{P}$ & 0.907 & 0.130 & 0.820 & 0.941 & 0.114 & 0.881 \\
\hline & & ET & 0.949 & 0.098 & 0.898 & 0.931 & 0.125 & 0.859 \\
\hline & & $\mathrm{S}$ & 0.844 & 0.172 & 0.684 & 0.947 & 0.115 & 0.880 \\
\hline & \multirow{3}{*}{$\begin{array}{c}\text { Data } \\
\text { Standardization }\end{array}$} & SPI & 0.958 & 0.088 & 0.917 & 0.960 & 0.094 & 0.919 \\
\hline & & SETI & 0.957 & 0.089 & 0.915 & 0.943 & 0.111 & 0.887 \\
\hline & & SI & 0.953 & 0.093 & 0.908 & 0.956 & 0.099 & 0.911 \\
\hline
\end{tabular}


Table 4. Assessment of runoff reconstruction and prediction at My Thuan-Can Tho (MT-CT) station pair, and Tan Chau-Chau Doc (TC-CD) station pair over the whole upstream area.

\begin{tabular}{|c|c|c|c|c|c|c|c|c|}
\hline \multirow{2}{*}{ Station } & \multirow{2}{*}{ Methods } & \multirow{2}{*}{ Data/Index } & \multicolumn{3}{|c|}{ Reconstruction } & \multicolumn{3}{|c|}{ Prediction } \\
\hline & & & PCC & NRMSE & NSE & PCC & NRMSE & NSE \\
\hline \multirow{18}{*}{$\begin{array}{l}\mathrm{MT}-\mathrm{CT} \\
\text { pair }\end{array}$} & \multirow{5}{*}{ Linear Regression } & NDVI & 0.901 & 0.115 & 0.812 & 0.914 & 0.129 & 0.831 \\
\hline & & LST & 0.850 & 0.140 & 0.723 & 0.749 & 0.214 & 0.537 \\
\hline & & $\mathrm{P}$ & 0.919 & 0.105 & 0.844 & 0.926 & 0.121 & 0.850 \\
\hline & & ET & 0.873 & 0.130 & 0.762 & 0.837 & 0.174 & 0.692 \\
\hline & & $\mathrm{S}$ & 0.966 & 0.069 & 0.933 & 0.960 & 0.092 & 0.915 \\
\hline & \multirow{5}{*}{ ANN } & NDVI & 0.910 & 0.111 & 0.826 & 0.921 & 0.125 & 0.840 \\
\hline & & LST & 0.827 & 0.154 & 0.664 & 0.792 & 0.208 & 0.561 \\
\hline & & $\mathrm{P}$ & 0.922 & 0.104 & 0.846 & 0.934 & 0.116 & 0.864 \\
\hline & & ET & 0.896 & 0.119 & 0.800 & 0.868 & 0.163 & 0.728 \\
\hline & & $\mathrm{S}$ & 0.973 & 0.063 & 0.944 & 0.970 & 0.083 & 0.930 \\
\hline & \multirow{5}{*}{ LSTM } & NDVI & 0.913 & 0.109 & 0.830 & 0.922 & 0.125 & 0.841 \\
\hline & & LST & 0.831 & 0.154 & 0.662 & 0.801 & 0.209 & 0.554 \\
\hline & & $\mathrm{P}$ & 0.920 & 0.107 & 0.836 & 0.925 & 0.123 & 0.847 \\
\hline & & ET & 0.900 & 0.117 & 0.806 & 0.871 & 0.162 & 0.733 \\
\hline & & $S$ & 0.977 & 0.057 & 0.954 & 0.972 & 0.077 & 0.939 \\
\hline & \multirow{3}{*}{$\begin{array}{c}\text { Data } \\
\text { Standardization }\end{array}$} & SPI & 0.985 & 0.047 & 0.968 & 0.927 & 0.122 & 0.848 \\
\hline & & SETI & 0.940 & 0.090 & 0.884 & 0.942 & 0.114 & 0.867 \\
\hline & & SI & 0.981 & 0.052 & 0.961 & 0.978 & 0.072 & 0.947 \\
\hline \multirow{18}{*}{$\begin{array}{l}\text { TC-CD } \\
\text { pair }\end{array}$} & \multirow{5}{*}{ Linear Regression } & NDVI & 0.923 & 0.117 & 0.855 & 0.908 & 0.141 & 0.820 \\
\hline & & LST & 0.861 & 0.156 & 0.742 & 0.755 & 0.222 & 0.552 \\
\hline & & $\mathrm{P}$ & 0.931 & 0.112 & 0.867 & 0.925 & 0.128 & 0.851 \\
\hline & & ET & 0.897 & 0.136 & 0.804 & 0.839 & 0.183 & 0.697 \\
\hline & & $\mathrm{S}$ & 0.968 & 0.077 & 0.937 & 0.955 & 0.101 & 0.907 \\
\hline & \multirow{5}{*}{ ANN } & NDVI & 0.934 & 0.110 & 0.872 & 0.916 & 0.135 & 0.834 \\
\hline & & LST & 0.833 & 0.172 & 0.686 & 0.763 & 0.225 & 0.540 \\
\hline & & $\mathrm{P}$ & 0.938 & 0.106 & 0.879 & 0.935 & 0.120 & 0.870 \\
\hline & & ET & 0.921 & 0.120 & 0.846 & 0.870 & 0.167 & 0.747 \\
\hline & & $S$ & 0.974 & 0.070 & 0.948 & 0.964 & 0.092 & 0.924 \\
\hline & \multirow{5}{*}{ LSTM } & NDVI & 0.937 & 0.108 & 0.876 & 0.917 & 0.134 & 0.837 \\
\hline & & LST & 0.844 & 0.168 & 0.699 & 0.786 & 0.219 & 0.566 \\
\hline & & $\mathrm{P}$ & 0.934 & 0.110 & 0.872 & 0.929 & 0.124 & 0.859 \\
\hline & & ET & 0.926 & 0.116 & 0.856 & 0.875 & 0.167 & 0.747 \\
\hline & & $\mathrm{S}$ & 0.976 & 0.067 & 0.952 & 0.966 & 0.089 & 0.929 \\
\hline & \multirow{3}{*}{$\begin{array}{c}\text { Data } \\
\text { Standardization }\end{array}$} & SPI & 0.986 & 0.052 & 0.971 & 0.932 & 0.124 & 0.861 \\
\hline & & SETI & 0.959 & 0.087 & 0.919 & 0.946 & 0.113 & 0.884 \\
\hline & & SI & 0.984 & 0.056 & 0.966 & 0.971 & 0.085 & 0.935 \\
\hline
\end{tabular}

As the baseline results, both the reconstructed and predicted $R$ time series from NDVI and LST captured well the ground-observed $R$ of the TC-CD station pair (Figure 5). Compared to the ground-observed $R$, discrepancies in peaks were apparent for the NDVI-reconstructed and predicted $R$, regardless of the employed models (i.e., linear regression, ANN, and LSTM). This was probably because vegetation index is not a direct water balance variable. Apparent discrepancies in troughs for the LST-reconstructed and predicted $R$ were probably attributable to fewer (more) sunny days during winter (spring), which caused abrupt decreases (increases) in surface temperature. This highlights the deficiency of using LST for $R$ reconstruction and prediction during winter and spring. The LST-reconstructed and predicted $R$ also presented variable time shifts across different years, indicating its unsuitability for runoff reconstruction and prediction. In any case, AI-based models displayed less than $1 \%$ improvement when compared to that reconstructed and predicted via linear regression (Table 3). 


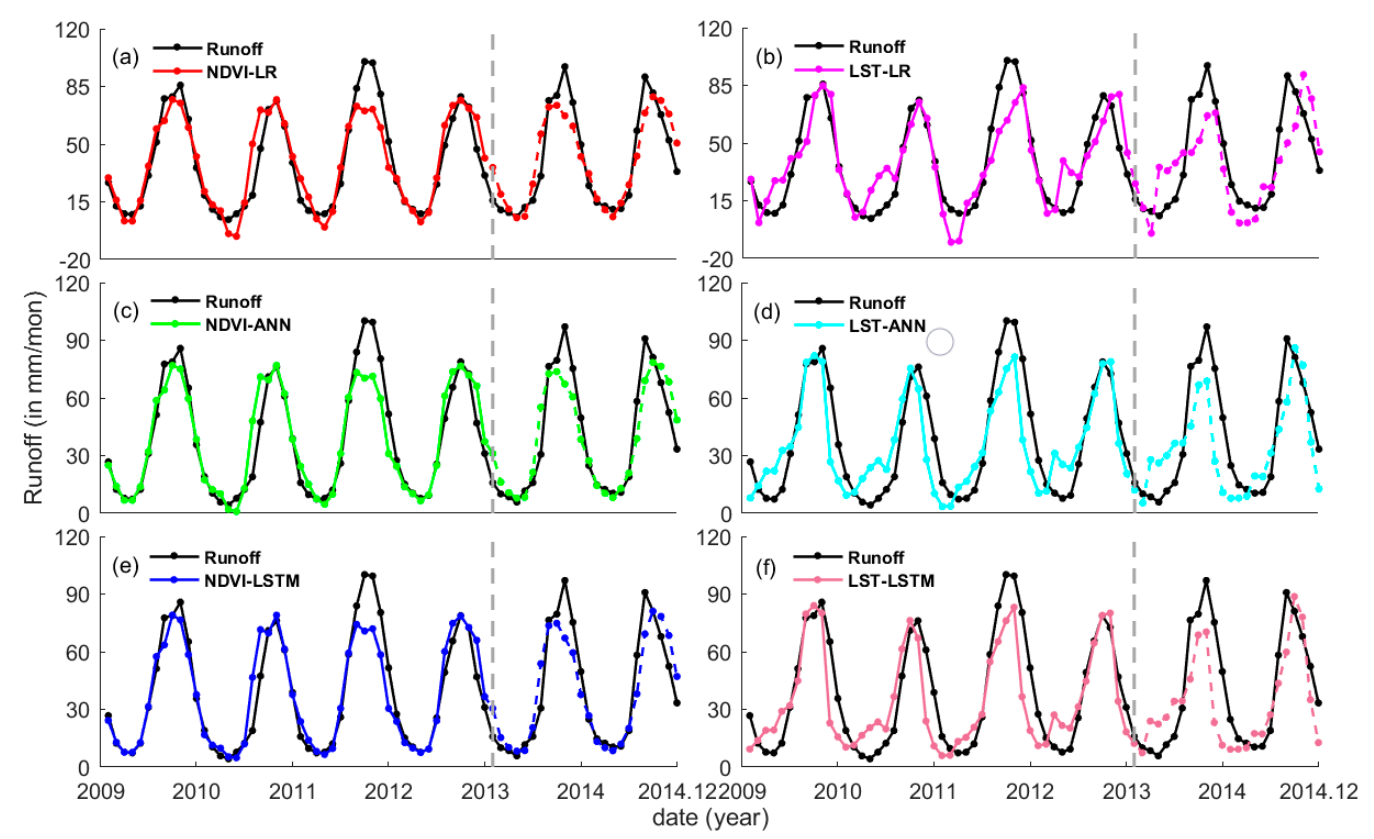

Figure 5. Reconstructed (solid line) and predicted (dash line) runoff at the TC-CD station pair based on NDVI and LST averaged over the whole upstream area from the Tibetan Plateau to the southern boundary of Cambodia via (a,b) linear regression (LR), (c,d) ANN, and (e,f) LSTM models.

Rs reconstructed and predicted from RS WBVs over Yunnan Province manifested a comparable performance to those of the passive RS surface variables (Table 3), except $R$ reconstructed from $S$ with the lowest PCC value (i.e., 0.809$)$ among RS WBVs. Nonetheless, $R$ reconstructed and predicted from $S$ over the whole upstream area yielded the highest PCC value (i.e., 0.966). $R$ reconstructed and predicted $P$ and $E T$ over the whole upstream area were also consistently better than those over Yunnan Province. This indicated the presence of spatially variable patterns of RS WBVs between the upstream and the downstream due to monsoon variability, while RS WBVs of the whole upstream area appeared to be a better representation of the basin. Moreover, apparent discrepancies were reduced for the $P$ - and $E T$-reconstructed and predicted $R s$ when compared to those reconstructed and predicted from the passive RS surface variables (Figures 6 and 7). Although those reconstructedand predicted from AI-based models generated a better performance than those of linear regression, the Rs based on standardized RS WBVs yielded even better outcomes (Figures 6-8) at capturing the peaks and the troughs, because the partly systematic influences were further mitigated by the data standardization process, as also demonstrated by the PCC, NRMSE, and NSE values, when compared to that of linear regression and AI-based models (Tables 3 and 4). In addition, no notable difference was found by comparing the $R$ reconstructed and predicted from MT-CT stations with that of TC-CD stations when RS WBVs of the whole upstream area were being employed, indicating negligible ocean tidal backwater effect.

Overall, most reconstructed and predicted Rs were shown to have PCC values larger than 0.9. Comparing RS WBVs with their standardizations, the reconstructed $R s$ based on the standardization yielded a $2-6 \%$ further increase in terms of PCC, NRMSE, and NSE values. The predicted $R$ based on the standardized $S$ over the whole upstream area resulted in the highest PCC (i.e., 0.978) and NSE (i.e., 0.947), and the lowest NRMSE (i.e., 0.072). This further demonstrated that the standardization was an effective technique in filtering out other environmental influences. After all, careful selection of the time span for the $R$ reconstruction was essential to the passive RS surface variables. Note that the NRMSE values during prediction were, in general, lower than those during reconstruction, because 24 (48) monthly data points were used during prediction (reconstruction) assessment. Moreover, the maximum range between the maximum and minimum runoff values during 2013-2014 was smaller than that during 2009-2012. 


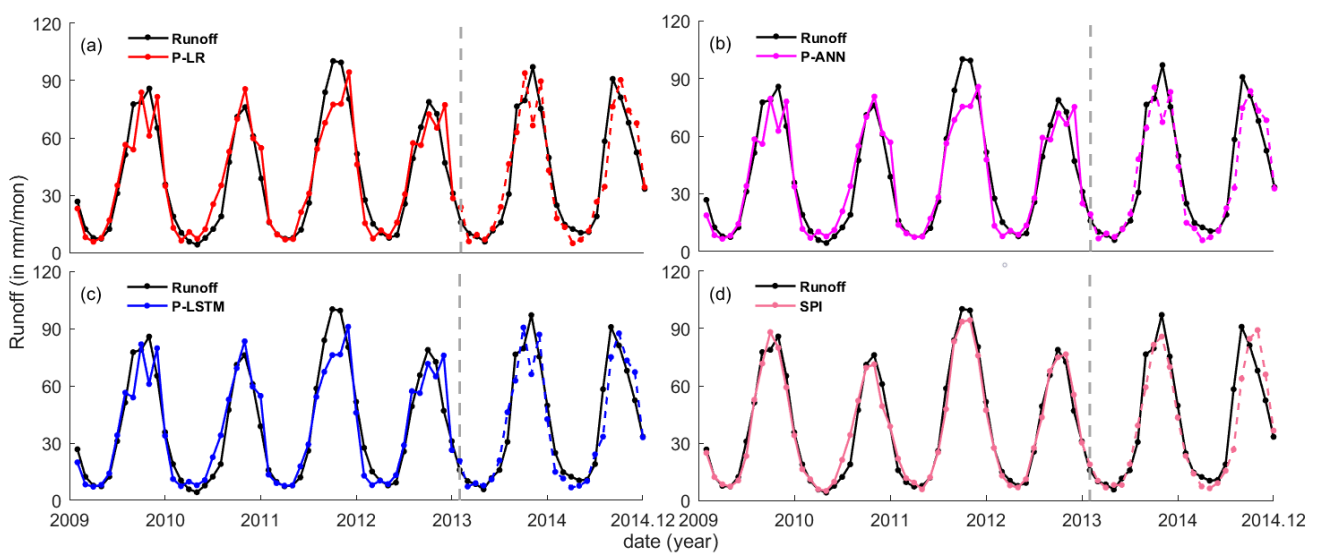

Figure 6. Reconstructed (solid line) and predicted (dash line) runoff at TC-CD station pair, based on remotely sensed precipitation $(P)$ averaged over the whole upstream area from Tibetan Plateau to southern boundary of Cambodia via (a) linear regression (LR), (b) ANN, (c) LSTM, and (d) data standardization.

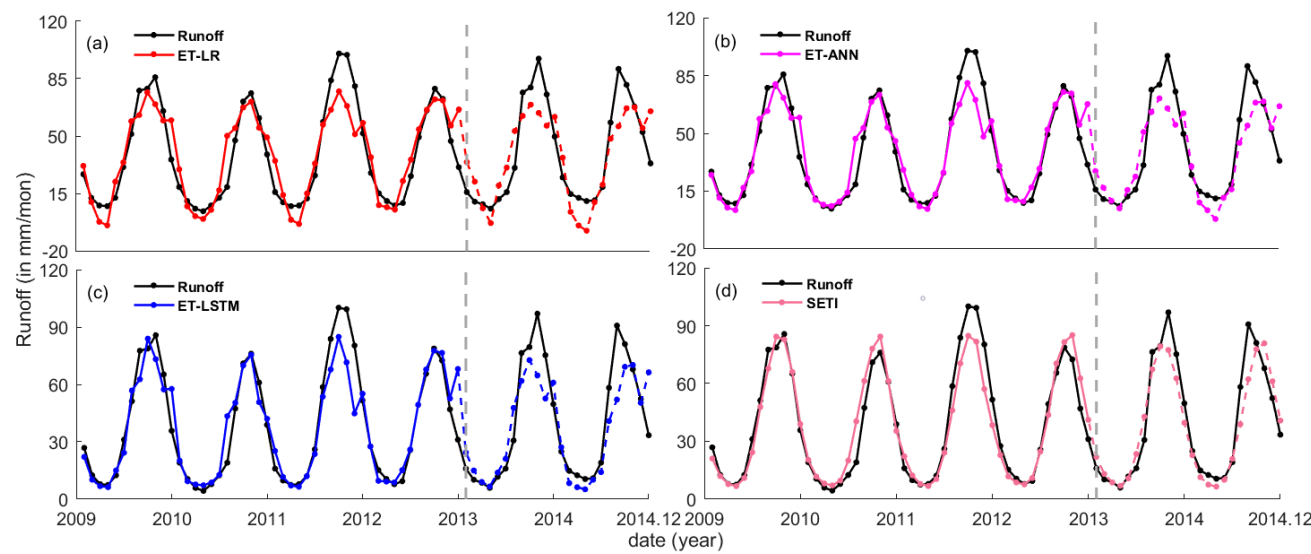

Figure 7. Reconstructed (solid line) and predicted (dash line) runoff at the TC-CD station pair based on remotely sensed evapotranspiration (ET) averaged over the whole upstream area from the Tibetan Plateau to the southern boundary of Cambodia via (a) linear regression (LR), (b) ANN, (c) LSTM, and (d) data standardization.

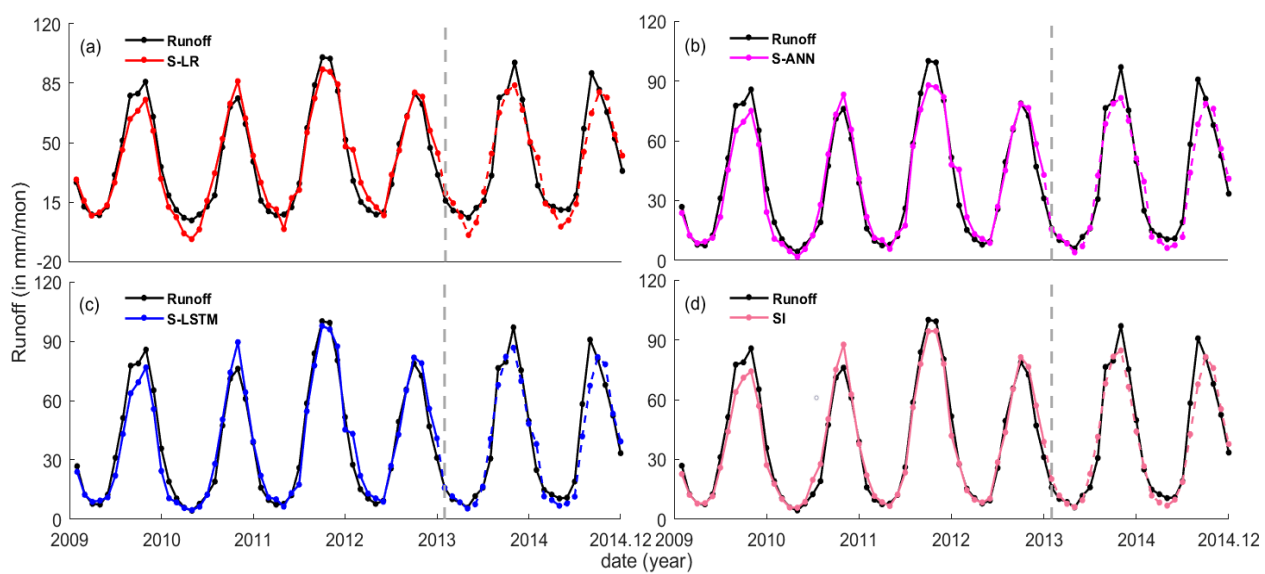

Figure 8. Reconstructed (solid line) and predicted (dash line) runoff at the TC-CD station pair based on remotely sensed water storage $(S)$ averaged over the whole upstream area from the Tibetan Plateau to the southern boundary of Cambodia via (a) linear regression (LR), (b) ANN, (c) LSTM, and (d) data standardization. 
Remaining errors might still exist. These include the presence of systematic errors in our model, unknown environmental signals in the RS WBVs, and variable time shifts across different years between the Mekong Basin upstream and the estuary downstream. Moreover, in-situ discharge time series in the river delta is needed for model reconstruction. These are the limitations of this study.

\section{Conclusions}

With the passive remotely-sensed (RS) surface variables (e.g., NDVI and LST) along with AI-based models as baseline results, we examined the temporal prediction performance of monthly runoff $(R)$ at the Mekong Delta reconstructed from the upstream remotely-sensed water balance variables (RS WBVs) and their standardizations, which should present more direct causal relationships and mitigate the environmental influences, such as ENSO events and hydrological extremes.

Through linear regression, we found that the reconstructed and predicted Rs based on the RS WBVs were comparable to those based on the passive RS surface variables. The reconstructed and predicted Rs via AI-based models showed less than $1 \%$ improvement over those of linear regression. With the presented standardization approach in this study, the reconstructed and predicted Rs based on the standardized RS WBVs yielded a $2-6 \%$ further increase in terms of all assessment indicators when compared to the RS WBVs without standardization. The $R$ predicted from standardized water storage averaged over the whole upstream area yielded the highest PCC (i.e., 0.978) and NSE (i.e., 0.947), and the lowest NRMSE (i.e., 0.072). This further indicated the ability of data standardization to mitigate environment influences.

Further study lies in a sensitivity analysis of the standardization process employing different data time periods for assessing the potential influence on the reconstruction and prediction performances under different intensities of monsoonal climate. This in turn provides a more comprehensive assessment of the reconstruction and prediction of $R$ at a higher sampling rate.

Author Contributions: Conceptualization, H.S.F.; methodology, H.S.F.; software, H.S.F. and L.Z.; validation, H.S.F., L.Z.; formal analysis, L.Z., H.S.F., H.J.; investigation, L.Z. and H.J.; resources, H.S.F.; data curation, H.S.F.; writing-original draft preparation, H.S.F.; writing-review and editing, H.S.F. and L.Z.; visualization, L.Z.; supervision, H.S.F.; project administration, H.S.F.; funding acquisition, H.S.F. All authors have read and agreed to the published version of the manuscript.

Funding: This research was funded by the National Natural Science Foundation of China (NSFC), grant numbers 41974003 and 41674007.

Acknowledgments: The authors appreciate the river water discharge data obtained from the Mekong River Commission (MRC), purchased using NSFC Grant No. 41374010.

Conflicts of Interest: The authors declare no conflict of interest.

\section{References}

1. Vörösmarty, C.; Askew, A.; Grabs, W.; Barry, R.; Birkett, C.; Döll, P.; Goodison, B.; Hall, A.; Jenne, R.; Kitaev, L. Global water data: A newly endangered species. Eos Trans. Am. Geophys. Union 2001, 82, 54-58. [CrossRef]

2. Sneeuw, N.; Lorenz, C.; Devaraju, B.; Tourian, M.J.; Riegger, J.; Kunstmann, H.; Bardossy, A. Estimating runoff using hydro-geodetic approaches. Surv. Geophys. 2014, 35, 1333-1359. [CrossRef]

3. Wen, X.; Hu, D.; Cao, B.; Shen, S.; Tang, X. Dynamics change of Honghu lake's water surface area and its driving force analysis based on remote sensing technique and TOPMODEL model. IOP Conf. Ser. Earth Environ. Sci. 2014, 17, 012130. [CrossRef]

4. Townsend, P.A.; Walsh, S.J. Modeling floodplain inundation using an integrated GIS with radar and optical remote sensing. Geomorphology 1998, 21, 295-312. [CrossRef]

5. Yue, W.; Xu, J.; Tan, W. The relationship between land surface temperature and NDVI with remote sensing: Application to shanghai Landsat 7 ETM+ data. Int. J. Remote Sens. 2007, 28, 3205-3226. [CrossRef]

6. Pan, F.; Nichols, J. Remote sensing of river stage using the cross-sectional inundation area-river stage relationship (IARSR) constructed from digital elevation model data. Hydrol. Process. 2013, 27, 3596-3606. [CrossRef] 
7. Fok, H.S.; He, Q.; Chun, K.P.; Zhou, Z.; Chu, T. Application of ENSO and drought indices for water level reconstruction and prediction: A case study in the lower Mekong river estuary. Water 2018, 10, 58. [CrossRef]

8. Fok, H.S.; He, Q. Water level reconstruction based on satellite gravimetry in the Yangtze River Basin. ISPRS Int. J. Geo-Inf. 2018, 7, 286. [CrossRef]

9. Frappart, F.; Minh, K.D.; L’Hermitte, J.; Cazenave, A.; Ramillien, G.; Le Toan, T.; Mognard-Campbell, N. Water volume change in the lower Mekong from satellite altimetry and imagery data. Geophys. J. Int. 2006, 167, 570-584. [CrossRef]

10. Calmant, S.; Seyler, F.; Cretaux, J.F. Monitoring continental surface waters by satellite altimetry. Surv. Geophys. 2008, 29, 247-269. [CrossRef]

11. Beven, K.J. Rainfall-Runoff Modelling: The Primer; John Wiley Sons Chichester: Hoboken, NJ, USA, 2001.

12. Tourian, M.J.; Sneeuw, N.; Bárdossy, A. A quantile function approach to discharge estimation from satellite altimetry (ENVISAT). Water Resour. Res. 2013, 49, 4174-4186. [CrossRef]

13. Kouraev, A.V.; Zakharova, E.A.; Samain, O.; Mognard, N.M.; Cazenave, A. Ob'river discharge from TOPEX/Poseidon satellite altimetry (1992-2002). Remote Sens. Environ. 2004, 93, 238-245. [CrossRef]

14. Birkinshaw, S.J.; O'donnell, G.M.; Moore, P.; Kilsby, C.G.; Fowler, H.J.; Berry, P.A.M. Using satellite altimetry data to augment flow estimation techniques on the Mekong River. Hydrol. Process. 2010, 24, 3811-3825. [CrossRef]

15. Paiva, R.C.D.; Collischonn, W.; Bonnet, M.P.; De Goncalves, L.G.G.; Calmant, S.; Getirana, A.; Santos da Silva, J. Assimilating in situ and radar altimetry data into a large-scale hydrologic-hydrodynamic model for streamflow forecast in the Amazon. Hydrol. Earth Syst. Sci. 2013, 17, 2929-2946. [CrossRef]

16. Tourian, M.J.; Schwatke, C.; Sneeuw, N. River discharge estimation at daily resolution from satellite altimetry over an entire river basin. J. Hydrol. 2017, 546, 230-247. [CrossRef]

17. Sulistioadi, Y.B.; Tseng, K.H.; Shum, C.K.; Hidayat, H.; Sumaryono, M.; Suhardiman, A.; Setiawan, F.; Sunarso, S. Satellite radar altimetry for monitoring small rivers and lakes in Indonesia. Hydrol. Earth Syst. Sci. 2015, 19, 341-359. [CrossRef]

18. Wahr, J.; Swenson, S.; Zlotnicki, V.; Velicogna, I. Time-variable gravity from GRACE: First results. Geophys. Res. Lett. 2004, 31, L11501. [CrossRef]

19. Crowley, J.W.; Mitrovica, J.X.; Bailey, R.C.; Tamisiea, M.E.; Davis, J.L. Land water storage within the Congo Basin inferred from GRACE satellite gravity data. Geophys. Res. Lett. 2006, 33, L19402. [CrossRef]

20. Riegger, J.; Tourian, M.J. Characterization of runoff-storage relationships by satellite gravimetry and remote sensing. Water Resour. Res. 2014, 50, 3444-3466. [CrossRef]

21. Sproles, E.A.; Reager, J.T.; Leibowitz, S.G. GRACE storage-runoff hystereses reveal the dynamics of regional watersheds. Hydrol. Earth Syst. Sci. 2015, 19, 3253-3272. [CrossRef]

22. Syed, T.H.; Famiglietti, J.S.; Chambers, D.P. GRACE-based estimates of terrestrial freshwater discharge from basin to continental scales. J. Hydrometeorol. 2009, 10, 22-40. [CrossRef]

23. Ferreira, V.G.; Gong, Z.; He, X.; Zhang, Y.; Andam-Akorful, S.A. Estimating total discharge in the Yangtze River Basin using satellite-based observations. Remote Sens. 2013, 5, 3415-3430. [CrossRef]

24. Chen, Y.; Fok, H.S.; Ma, Z.; Tenzer, R. An improved remotely-sensed total basin discharge with its seasonal error characterization in the Yangtze River Basin. Sensors 2019, 19, 3386. [CrossRef] [PubMed]

25. Box, G.E.P.; Jenkins, G.M. Times Series Analysis: Forecasting and Control; Holden-Day: San Francisco, CA, USA, 1970.

26. Hassoun, M.H. Fundamentals of Artificial Neural Networks; MIT press: Cambridge, MA, USA, 1995.

27. Rumelhart, D.E.; Hinton, G.E.; Williams, R.J. Learning representations by back-propagating errors. Nature 1986, 323, 533-536. [CrossRef]

28. Wang, W.-C.; Chau, K.-W.; Cheng, C.-T.; Qiu, L. A comparison of performance of several artificial intelligence methods for forecasting monthly discharge time series. J. Hydrol. 2009, 374, 294-306. [CrossRef]

29. Ferreira, V.G.; Montecino, H.C.; Ndehedehe, C.E.; Heck, B.; Gong, Z.; de Freitas, S.R.C.; Westerhaus, M. Space-based observations of crustal deflections for drought characterization in brazil. Sci. Total Environ. 2018, 644, 256-273. [CrossRef] [PubMed]

30. Jones, P.D.; Hulme, M. Calculating regional climatic time series for temperature and precipitation: Methods and illustrations. Int. J. Climatol. 1996, 16, 361-377. [CrossRef]

31. Tang, J.; Yin, X.A.; Yang, P.; Yang, Z.F. Assessment of contributions of climatic variation and human activities to streamflow changes in the Lancang River, China. Water Resour. Manag. 2014, 28, 2953-2966. [CrossRef] 
32. Fok, H.S.; Iz, H.B.; Shum, C.K.; Yi, Y.; Andersen, O.; Braun, A.; Chao, Y.; Han, G.; Kuo, C.Y.; Matsumoto, K.; et al. Evaluation of ocean tide models used for Jason-2 altimetry corrections. Mar. Geod. 2010, 33, 285-303. [CrossRef]

33. Anthony, E.J.; Brunier, G.; Besset, M.; Goichot, M.; Dussouillez, P.; Nguyen, V.L. Linking rapid erosion of the Mekong river delta to human activities. Sci. Rep. 2015, 5, 14745. [CrossRef]

34. Gugliotta, M.; Saito, Y.; Nguyen, V.L.; Ta, T.K.O.; Tamura, T. Sediment distribution and depositional processes along the fluvial to marine transition zone of the Mekong River delta, Vietnam. Sedimentology 2019, 66, 146-164. [CrossRef]

35. Kummu, M.; Tes, S.; Yin, S.; Adamson, P.; Józsa, J.; Koponen, J.; Richey, J.; Sarkkula, J. Water balance analysis for the Tonle Sap Lake-floodplain system. Hydrol. Process. 2014, 28, 1722-1733. [CrossRef]

36. Frappart, F.; Biancamaria, S.; Normandin, C.; Blarel, F.; Bourrel, L.; Aumont, M.; Azemar, P.; Vu, P.L.; Le Toan, T.; Lubac, B.; et al. Influence of recent climatic events on the surface water storage of the Tonle Sap Lake. Sci. Total Environ. 2018, 636, 1520-1533. [CrossRef]

37. Huang, S.; Krysanova, V.; Zhai, J.; Su, B. Impact of intensive irrigation activities on river discharge under agricultural scenarios in the semi-arid Aksu river basin, northwest China. Water Resour. Manag. 2015, 29, 945-959. [CrossRef]

38. Zampieri, M.; Carmona Garcia, G.; Dentener, F.; Gumma, M.; Salamon, P.; Seguini, L.; Toreti, A. Surface freshwater limitation explains worst rice production anomaly in India in 2002. Remote Sens. 2018, 10, 244. [CrossRef]

39. Jung, H.C.; Alsdorf, D.; Moritz, M.; Lee, H.; Vassolo, S. Analysis of the relationship between flooding area and water height in the Logone floodplain. Phys. Chem. Earth Parts A/B/C 2011, 36, 232-240. [CrossRef]

40. Hirpa, F.A.; Hopson, T.M.; De Groeve, T.; Brakenridge, G.R.; Gebremichael, M.; Restrepo, P.J. Upstream satellite remote sensing for river discharge forecasting: Application to major rivers in South Asia. Remote Sens. Environ. 2013, 131, 140-151. [CrossRef]

41. Tarpanelli, A.; Amarnath, G.; Brocca, L.; Massari, C.; Moramarco, T. Discharge estimation and forecasting by MODIS and altimetry data in Niger-Benue River. Remote Sens. Environ. 2017, 195, 96-106. [CrossRef]

42. Li, X.; Liu, J.P.; Saito, Y.; Nguyen, V.L. Recent evolution of the Mekong Delta and the impacts of dams. Earth-Sci. Rev. 2017, 175, 1-17. [CrossRef]

43. Lu, X.X.; Li, S.; Kummu, M.; Padawangi, R.; Wang, J.J. Observed changes in the water flow at Chiang Saen in the lower Mekong: Impacts of Chinese dams? Quat. Int. 2014, 336, 145-157. [CrossRef]

44. Cochrane, T.A.; Arias, M.E.; Piman, T. Historical impact of water infrastructure on water levels of the Mekong River and the Tonle Sap system. Hydrol. Earth Syst. Sci. 2014, 18, 4529-4541. [CrossRef]

45. Wahr, J.; Molenaar, M.; Bryan, F. Time variability of the Earth's gravity field: Hydrological and oceanic effects and their possible detection using GRACE. J. Geophys. Res. Solid Earth 1998, 103, 30205-30229. [CrossRef]

46. Cheng, M.; Tapley, B.D. Variations in the Earth's oblateness during the past 28 years. J. Geophys. Res. 2004, 109. [CrossRef]

47. Swenson, S.; Chambers, D.; Wahr, J. Estimating geocenter variations from a combination of grace and ocean model output. J. Geophys. Res. 2008, 113, B08410. [CrossRef]

48. Ramillien, G.; Frappart, F.; Cazenave, A.; Güntner, A. Time variations of land water storage from an inversion of 2 years of GRACE geoids. Earth. Planet. Sci. Lett. 2005, 235, 283-301. [CrossRef]

49. Swenson, S.; Wahr, J. Post-processing removal of correlated errors in GRACE data. Geophys. Res. Lett. 2006, 33. [CrossRef]

50. Mu, Q.; Zhao, M.; Running, S.W. Improvements to a MODIS global terrestrial evapotranspiration algorithm. Remote Sens. Environ. 2011, 115, 1781-1800. [CrossRef]

51. Liu, Z.; Ostrenga, D.; Teng, W.; Kempler, S. Tropical Rainfall Measuring Mission (TRMM) precipitation data and services for research and applications. Bull. Am. Meteorol. Soc. 2012, 93, 1317-1325. [CrossRef]

52. Huffman, G.J.; Adler, R.F.; Bolvin, D.T.; Gu, G.; Nelkin, E.J.; Bowman, K.P.; Hong, Y.; Stocker, E.F.; Wolff, D.B. The TRMM Multi-satellite Precipitation Analysis: Quasi-Global, Multi-Year, Combined-Sensor Precipitation Estimates at Fine Scale. J. Hydrometeorol. 2007, 8, 38-55. [CrossRef]

53. McKee, T.B.; Doesken, N.J.; Kleist, J. The relationship of drought frequency and duration to time scales. In Proceedings of the 8th Conference on Applied Climatology, Anaheim, CA, USA, 17-22 January 1993; American Meteorological Society: Boston, MA, USA, 1993. 
54. Kumar, M.N.; Murthy, C.S.; Sai, M.V.R.S.; Roy, P.S. On the use of Standardized Precipitation Index (SPI) for drought intensity assessment. Meteorol. Appl. 2009, 16, 381-389. [CrossRef]

55. Räsänen, T.A.; Kummu, M. Spatiotemporal influences of ENSO on precipitation and flood pulse in the Mekong River Basin. J. Hydrol. 2013, 476, 154-168. [CrossRef]

56. Fok, H.S.; Zhou, L.; Liu, Y.; Ma, Z.; Chen, Y. Upstream GPS Vertical displacement and its standardization for mekong river basin surface runoff reconstruction and estimation. Remote Sens. 2020, 12, 18. [CrossRef]

57. Nash, J.E.; Sutcliffe, J.V. River flow forecasting through conceptual models part I-A discussion of principles. J. Hydrol. 1970, 10, 282-290. [CrossRef]

58. Gupta, H.V.; Kling, H.; Yilmaz, K.K.; Martinez, G.F. Decomposition of the mean squared error and NSEperformance criteria: Implications for improving hydrological modelling. J. Hydrol. 2009, 377, 80-91. [CrossRef]

59. Ritter, A.; Muñoz-Carpena, R. Performance evaluation of hydrological models: Statistical significance for reducing subjectivity in goodness-of-fit assessments. J. Hydrol. 2013, 480, 33-45. [CrossRef]

60. Cheng, K.-S.; Lien, Y.-T.; Wu, Y.-C.; Su, Y.-F. On the criteria of model performance evaluation for real-time flood forecasting. Stoch. Environ. Res. Risk Assess. 2017, 31, 1-24. [CrossRef]

61. Li, Y.; Wang, W.; Lu, H.; Khem, S.; Yang, K.; Huang, X. Evaluation of three satellite-based precipitation products over the lower mekong river basin using rain gauge observations and hydrological modeling. IEEE J-STARS 2019, 12, 2357-2373. [CrossRef]

62. Jiang, L.; Islam, S.; Carlson, T.N. Uncertainties in latent heat flux measurement and estimation: Implications for using a simplified approach with remote sensing data. Can. J. Remote Sens. 2004, 30, 769-787. [CrossRef]

63. Kalma, J.D.; McVicar, T.R.; McCabe, M.F. Estimating land surface evaporation: A review of methods using remotely sensed surface temperature data. Surv. Geophys. 2008, 29, 421-469. [CrossRef]

(C) 2020 by the authors. Licensee MDPI, Basel, Switzerland. This article is an open access article distributed under the terms and conditions of the Creative Commons Attribution (CC BY) license (http://creativecommons.org/licenses/by/4.0/). 